\title{
Prototipe double acting cylinder transparan sebagai media pembelajaran sistem hidrolik
}

\author{
Tri Pratomo ${ }^{1 *}$, Rina Dwi Yani ${ }^{2}$, Maryono Effendi ${ }^{3}$, Dovian Iswanda ${ }^{4}$, Alban \\ Naufal $^{5}$, Devi Andriani 6 \\ 1,2,3,4,5,6 Jurusan Teknik Mesin, Politeknik Negeri Pontianak \\ Jl. Jenderal Achmad Yani Pontianak, Kalimantan Barat, Indonesia \\ ${ }^{*}$ Corresponding author: tpratomo217@gmail.com
}

\begin{abstract}
Double acting cylinders in its application are widely used in the industry and are often applied in maintenance or repair instruments. The purpose of this research is to design and make a double acting cylinder so that the movement of the hydraulic cylinder its fluid flow can be seen clearly and easily implemented in the movement process, especially in the learning process. The research employs experimental method by directly design a transparent double acting cylinder. This transparent double acting cylinder will later be applied to the hydraulic trainer. The steps taken were determining the transparent material, making material samples for tensile tests, designing and making hydraulic cylinders, conducting hydraulic cylinder tests using Autodesk Inventor 2019. From the test results of hydraulic cylinders made from acrylic using Autodesk Inventor 2019, the minimum pressure that occurs is 1,456 MPa and the maximum pressure that occurs is 6,573 $\mathrm{MPa}$, in operation, the recommended pressure 1,456 to 5,551 MPa, double acting transparent cylinder which has a transparent hydraulic cylinder length of $250 \mathrm{~mm}$, thickness $11.4 \mathrm{~mm}$, hydraulic cylinder inner diameter $32 \mathrm{~mm}$, hydraulic cylinder locking uses 4 bolts with size M8, design pressure $23 \mathrm{~kg} / \mathrm{cm}^{2}$.
\end{abstract}

Keywords: hydraulic system, double acting cylinder, transparent.

\begin{abstract}
Abstrak
Dalam aplikasinya, double acting cylinder banyak digunakan di industri dan sering diaplikasikan pada alat-alat bantu perawatan atau perbaikan. Tujuan penelitian ini adalah mendesain dan membuat double acting cylinder transparan agar pergerakan cylinder tube serta aliran fluidanya dapat terlihat dengan jelas mudah dipahami dalam proses pergerakannya, terutama pada proses pembelajaran. Metode penelitian yang digunakan adalah metode eksperimental yaitu dengan melakukan rancang bangun secara langsung double acting cylinder transparan. Double acting cylinder transparan ini nantinya akan diaplikasikan pada hydraulic trainer. Tahapan yang dilakukan adalah menentukan bahan yang transparan, membuat sampel bahan untuk dilakukan uji tarik, mendesain dan membuat cylinder tube, melakukan uji cylinder tube menggunakan Autodesk Inventor 2019. Darihasil uji cylinder tube berbahan akrilik dengan menggunakan Autodesk Inventor 2019, tekanan minimal yang terjadi 1,456 MPa dan tekanan maksimal yang terjadi 6,573 MPa, tekanan yang dianjurkan dalam pengoperasian 1,456-5,551 MPa, doubleacting cylinder transparan memiliki panjang cylinder tube $250 \mathrm{~mm}$, tebal cylinder tube 11,4 $\mathrm{mm}$, diameter dalam cylinder tube $32 \mathrm{~mm}$, penguncian cylinder tube menggunakan 4 baut dengan ukuran M8, tekanan rencana $23 \mathrm{~kg} / \mathrm{cm}^{2}$.
\end{abstract}

Kata kunci: sistem hidrolik, double acting cylinder, transparan

\section{Pendahuluan}

Sistem hidrolik pada dasarnya terdiri dari tiga komponen utama, sumber pembangkit tekanan, katup control, dan actuator hidrolik. Sistem hidrolik merupakan sistem saluran tertutup, dimana aliran fluida (oli) mengalir dari sumber pembangkit tekanan melalui pipa hidrolik 
atau selang hidrolik. Dengan kata lain, fluida yang mengalir pada sistem hidrolik tidak terlihat.

Actuator hidrolik merupakan komponen akhir dari sistem hidrolik yang menghasilkan gerak linier atau gerak rotasi. Actuator hidrolik terbagi menjadi 3, single acting cylinder, double acting cylinder dan hydraulic motor. Single dan double acting cylinder menghasilkan gerak linier dan hydraulic motor menghasilkan gerak rotasi.

Dalam aplikasinya, penggunaan double acting cylinder lebih banyak digunakan di industri atau digunakan pada peralatan yang memiliki sistem hidrolik. Untuk memudahkan pemahaman pergerakan cylinder tube serta aliran fluida pada sebuah sistem yang menggunakan sistem hidrolik, maka akan lebih mudah jika double acting cylinder dibuat transparan sehingga aliran fluida dapat terlihat masuk atau keluar dari double acting cylinder. Salah satu komponen yang penting dalam double acting cylinder adalah tabung silinder atau dikenal dengan cylinder tube. Cylinder tube ini memilki ketebalan tertentu, dimaksudkan untuk mampu menahan tekanan yang masuk ke dalamnya.

Untuk menghitung ketebalan cylinder tube perlu diperhatikan tingkat kekerasan dari bahan yang digunakan, jenis kekerasan bahan terdiri dari keras, sedang, dan lunak. Bahan yang digunakan untuk pembuatan double acting cylinder transparan pada penelitian ini masuk dalam jenis lunak, sehingga rumusan yang digunakan adalah Lame's Equation [1]. Selain itu rancang bangun double acting cylinder transparan harus memperhatikan dengan teliti terutama pada saat pengujian di rangkaian sistem hidrolik, kebocoran fluida harus dihindari agar double acting cylinder transparan bekerja maksimal [2]. Di samping itu juga harus memperhitungkan tekanan kerja pada double acting cylinder transparan agar tidak terjadi kerusakan pada arah aksial dari komponen yang bekerja di dalam cylinder tube [3].

Fokus penelitian ini adalah pada desain dan pembuatan cylinder tube transparan yang dirakit menjadi double acting cylinder transparan yang menghasilkan gerak linier atau gerak lurus. Gerakan maju dan mundur double acting cylinder transparan dikontrol oleh katup kontrol arah 4/2 atau menggunakan katup kontrol arah 4/3. Analisis cylinder tube transparan menggunakan software inventor versi 2019, terdiri dari analisis von mises stress, analisis displacement dan analisis safety factor. Hasil analisis tersebut merupakan dasar untuk proses pembuatan cylinder tube transparan.

Bahan dasar yang digunakan untuk membuat cylinder tube transparan adalah akrilik yang terdiri dari campuran antara resin dan katalis dengan perbandingan tertentu. Selain itu juga harus diperhitungkan ketebalan cylinder tube agar dapat menahan tekanan sehingga tidak terjadi kerusakan pada cylinder tube tersebut.

\section{Tinjauan Pustaka}

Untuk mendesain cylinder tube diperlukan data tekanan fluida (oli) yang ada di training unit hidrolik, bahan yang akan digunakan sebagai cylinder tube, diameter dalam dari cylinder tube dan ketersediaan seal hidrolik. Dalam penelitian ini direncanakan cylinder tube menggunakan akrilik.

Dalam penelitian ini perhitungan ketebalan cylinder tube menggunakan Lame's Equation [1], dimana bahan dasar pembuatan cylinder tube dikategorikan sebagai bahan yang lunak dan bersifat getas.

$$
\mathrm{t}=\frac{\mathrm{di}}{2}\left(\sqrt{\frac{\mathrm{ft}+\mathrm{P}}{\mathrm{ft}-\mathrm{P}}}-1\right)
$$

$\mathrm{t}$ adalah ketebalan cylinder tube (cm), di adalah diameter dalam cylinder tube (cm), ft adalah kekuatan tarik bahan $\left(\mathrm{kg} / \mathrm{cm}^{2}\right)$, dan $\mathrm{P}$ adalah tekanan fluida yang direncanakan $\left(\mathrm{kg} / \mathrm{cm}^{2}\right)$.

\section{Metode Penelitian}

Metode yang digunakan pada penelitian ini adalah metode eksperimental, yaitu dengan melakukan rancang bangun secara langsung double acting cylinder 
transparan. Double acting cylinder atau lebih dikenal dengan cylinder tube didesain terlebih dahulu meliputi perencanaan panjang cylinder tube, tebal cylinder tube, menyesuaikan ketersediaan seal hidrolik pada piston, tutup atas tutup bawah silinder serta memposisikan tata letak dan estetikanya.

Tahapan selanjutnya adalah membuat desain double acting cylinder untuk selanjutnya dilakukan proses perencanaan dan pembuatan komponen-komponen double acting cylinder transparan. Hal-hal teknis yang perlu diperhatikan dalam mendesain double acting cylinder transparan adalah sebagai berikut :

1. Melakukan studi literatur terkait dengan double acting cylinder transparan.

2. Melakukan studi bahan material yang dijadikan cylinder tube transparan.

3. Penghitungan ketebalan cylinder tube

4. Perencanaan tata letak dari komponen elemen mesin pada double acting cylinder transparan.

5. Pembuatan gambar desain double acting cylinder transparan meggunakan aplikasi Autodesk Inventor, dimulai dengan membuat sebuah model atau part yang akan dianalisis dan memilih material sesuai dengan perencanaan. Analisis cylinder tube untuk mendapatkan tekanan maksimal.

6. Pembuatan double acting cylinder transparan.

7. Melakukan uji coba operasi double acting cylinder transparan pada hydraulic trainer dan menganalisis unjuk kerjanya. dilakukan:

Berikut diagram alir penelitian yang

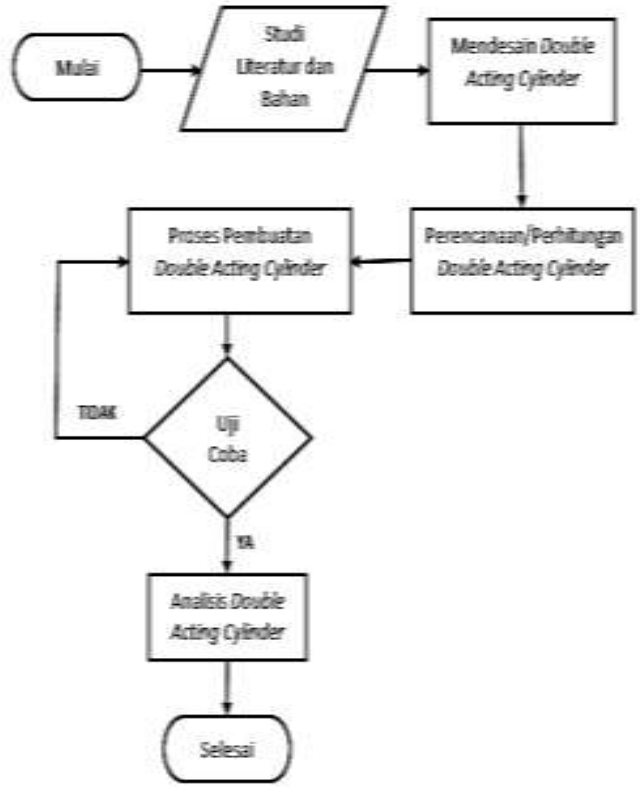

Gambar 1. Diagram Alir Penelitian

\section{Hasil dan Pembahasan}

Dari studi yang dilakukan, material yang akan digunakan sebagai bahan untuk membuat cylinder tube adalah akrilik. Akrilik merupakan hasil dari campuran antara resin dan bahan pengeras atau katalis. Dalam proses pencampuran, perbandingan antara resin dan katalis adalah 1 : 250, artinya untuk $250 \mathrm{ml}$ resin dicampur dengan $1 \mathrm{ml}$ katalis.

Dengan perbandingan tersebut peneliti membuat sampel akrilik seperti pada Gambar 2, yang nantinya akan diuji menggunakan Universal Testing Machine. Pengujian tersebut untuk mendapatkan kekuatan Tarik bahan akrilik yang digunakan untuk menghitung ketebalan cylinder tube. Pengujian sampel akrilik tersebut dilakukan di Laboratorium Pengujian Material dan Metrologi Jurusan Teknik Mesin Politeknik Negeri Pontianak.

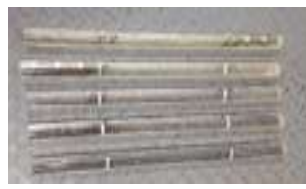

(a)

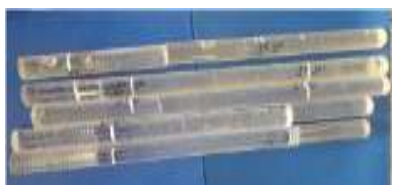

(b)
Gambar 2. Sampel akrilik. (a) Sebelum diuji (b) Setelah diuji

Pada pengujian tarik sampel akrilik yang dilakukan, rata-rata beban (load) yang 
diberikan adalah sebesar 1.943,6 kN, ratarata regangan (strain) sebesar $2,68 \%$, ratarata perpanjangan sampel (exstension) 10,73 $\mathrm{mm}$ dan rata-rata tegangan tarik maksimal (tensile maxs) 4,67 MPa. Hasil pengujian tarik selengkapnya dapat dilihat pada Tabel 1.

Tabel 1. Pengujian sampel akrilik

\begin{tabular}{lccll}
\hline & $\begin{array}{c}\text { Load } \\
(\mathrm{kN})\end{array}$ & $\begin{array}{c}\text { Strain } \\
(\%)\end{array}$ & $\begin{array}{l}\text { Extension } \\
(\mathrm{mm})\end{array}$ & $\begin{array}{l}\text { Tensile } \\
\text { Maxs } \\
(\mathrm{MPa})\end{array}$ \\
\hline Sampel 1 & 1.757 & 1,65 & 6,59 & 4,230 \\
\hline Sampel 2 & 1.888 & 2,43 & 9,71 & 4,624 \\
\hline Sampel 3 & 2.209 & 0,79 & 3,18 & 5,181 \\
\hline Sampel 4 & 2.054 & 1,28 & 5,13 & 4,939 \\
\hline Sampel 5 & 1.810 & 7,26 & 29,05 & 4,356 \\
\hline Evegare & $1.943,6$ & 2,68 & 10,73 & 4,67 \\
\hline
\end{tabular}

Dalam menghitung ketebalan cylinder tube, tegangan tarik yang digunakan adalah setengah dari tegangan tarik maksimal yaitu 2,3 $\mathrm{MPa}$ atau 23 bar. Hal ini dimaksudkan sebagai faktor keamanan bahan cylinder tube dan untuk mencegah terjadinya kerusakan atau pecah pada cylinder tube yang terbuat dari bahan akrilik.

Selanjutnya melakukan pengamatan di Hydraulic Trainer untuk mendapatkan data pendukung pada perhitungan ketebalan cylinder tube, pengaturan tekanan fluida, tata letak double acting cylinder pada hydraulic trainer serta katup kontrol arah yang akan digunakan. Hasil pengamatan dapat dilihat pada Tabel 2, pengamatan tersebut juga membandingkan peralatan di beberapa hydraulic trainer yang dimiliki Laboratorium Pneumatik Hidrolik [4]-[5]

Tabel 2. Pengamatan alat pendukung

\begin{tabular}{lll}
\hline Pengamatan & \multicolumn{1}{c}{ Hasil } & \multicolumn{1}{c}{ Ket } \\
\hline Manometer & Tekanan 100 Bar & Tersedia \\
\hline Relief Valve & Mengatur Tekanan & Tersedia \\
\hline Cylinder Tube & $\varnothing$ 32 mm & Di desain \\
\hline Tata Letak & Rel Pengunci & Tersedia \\
\hline $\begin{array}{l}\text { Katup Kontrol } \\
\text { Arah }\end{array}$ & Katup 4/2 dan & Tersedia \\
\hline
\end{tabular}

Dari hasil pengujian sampel akrilik dan pengamatan yang dilakukan di hydraulic trainer diperoleh data untuk melakukan perhitungan ketebalan cylinder tube seperti terlihat pada Tabel 3.
Tabel 3. Data perhitungan ketebalan

\begin{tabular}{lc}
\hline & Hasil \\
\hline Tekanan rencana (P) & $23 \mathrm{Bar}$ \\
\hline Diameter dalam silinder (di) & $32 \mathrm{~mm}$ \\
\hline Kekuatan Tarik akrilik (ft) & $46,7 \mathrm{Bar}$ \\
\hline
\end{tabular}

Tahapan berikutnya melakukan perhitungan ketebalan cylinder tube yang berbahan akrilik menggunakan Lame's Equation sesuai data pada Tabel 3

Dari perhitungan menggunakan Lame's Equation, ketebalan cylinder tube berbahan akrilik adalah 11,4 $\mathrm{mm}$, dengan panjang cylinder tube $250 \mathrm{~mm}$.

Desain cylinder tube transparan dapat dilihat pada Gambar 3 dan desain secara keseluruhan dapat dilihat pada Gambar 4 dan Gambar 5. Penggambaran desain cylinder tube dan desain double acting cylinder menggunakan software Autodesk Inventor 2019.

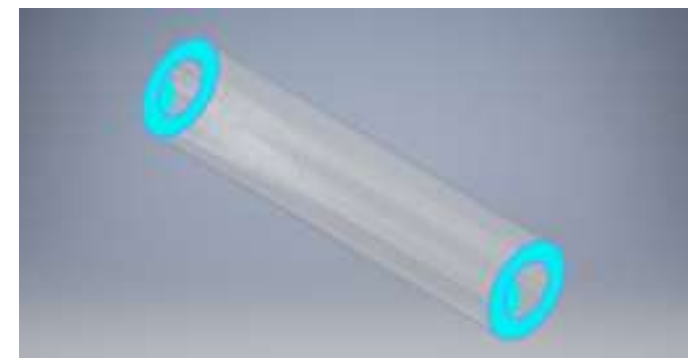

Gambar 3. Desain cylinder tube transparan

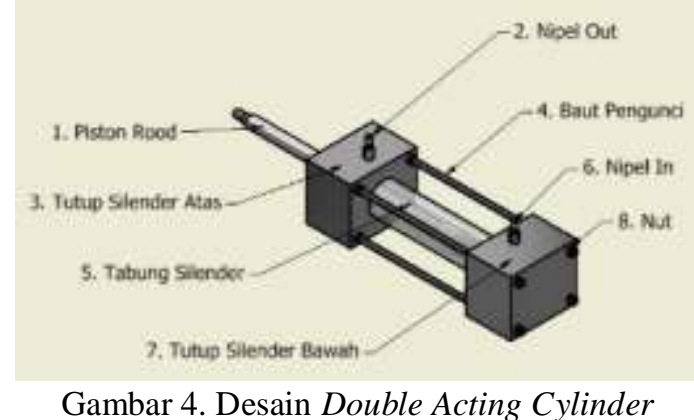

Double acting cylinder tersusun atas beberapa komponen yang mendukungnya yaitu; cylinder tube, tutup silinder, piston, piston rod, saluran oli hidrolik, seal hidrolik dan jenis penguncian tutup silinder [6].

Desain double acting cylinder transparan memiliki beberapa komponen yang mendukungnya:

1. Silinder transparan berfungsi sebagai wadah fluida atau oli hidrolik dan sebagai dudukan piston dan piston rod. 
2. Tutup silinder berfungsi sebagai penahan oli hidrolik agar tidak bocor, dimana bagian tutup ini dilapisi oleh seal pada bagian dalamnya. Selain itu pada tutup silinder terdapat dua saluran oli hidrolik.

3. Piston dan piston rod, piston berfungsi sebagai pembatas ruang antara oli hidrolik yang masuk melalui saluran masuk (nipple in) dan saluran keluar (nipple out). Piston memiliki dua seal yang terpasang pada dinding piston. Sedangkan piston rod berfungsi untuk menghasilkan gerak linier.

4. Baut pengunci terdiri dari empat buah baut sepanjang antara tutup silider hidrolik, jenis baut yang digunakan adalah poros berulir [7][8], berfungsi sebagai pengunci antara tutup silinder.

Untuk bagian dalam dari double acting cylinder dapat dilihat pada Gambar 5. Untuk melindungi double acting cylinder transparan dari kebocoran, maka dipasang seal hidrolik. Seal hidrolik terdiri dari dua buah seal hidrolik pada tutup bawah, dua seal hidrolik pada tutup atas dan dua seal hidrolik pada alur keluaran dari piston rod [9].

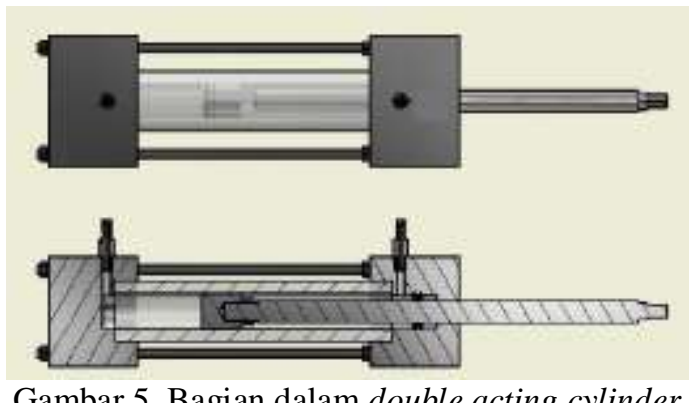

Gambar 5. Bagian dalam double acting cylinder

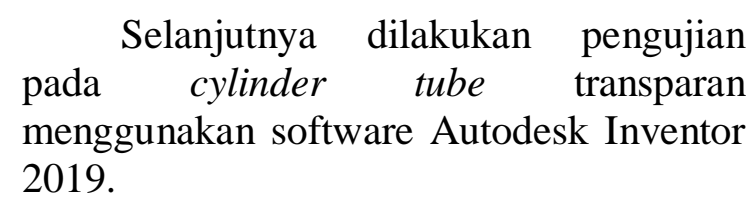

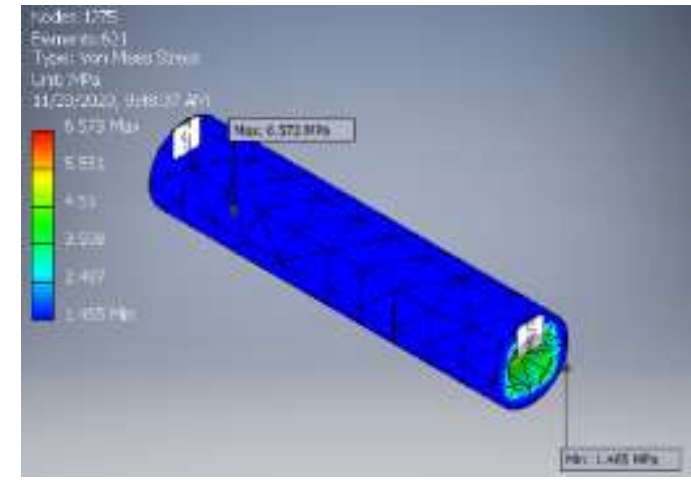

Gambar 6. Pengujian cylinder tube

Dari pengujian menggunakan inventor terlihat bahwa tekanan maksimal pada cylinder tube yang ditandai dengan warna merah adalah $6,573 \mathrm{MPa}$ atau 65,73 Bar. Tekanan ini merupakan tekanan maksimal yang dapat ditahan oleh cylinder tube transparan. Tetapi tekanan ini tidak dapat digunakan pada pengoperasian, jika dilakukan maka cylinder tube transparan akan mengalami kerusakan atau pecah.

Kemudian tutup silinder dan pengunci silinder di-assembly, untuk memperlihatkan bagian dalam dari cylinder tube trasparan, maka dilakukan potongan penuh [10] dari cylinder tube transparan, seperti pada Gambar 7.

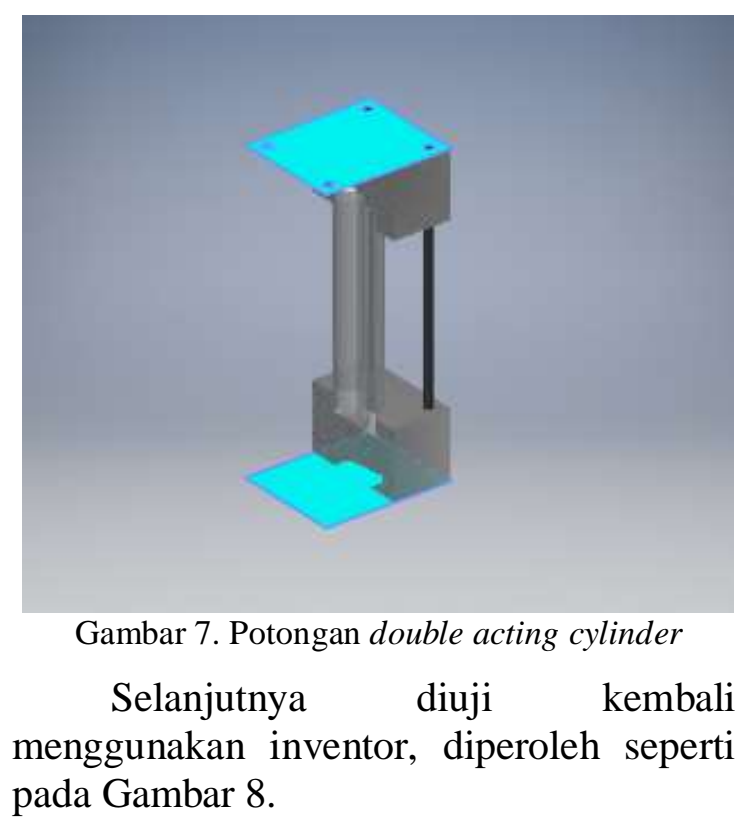




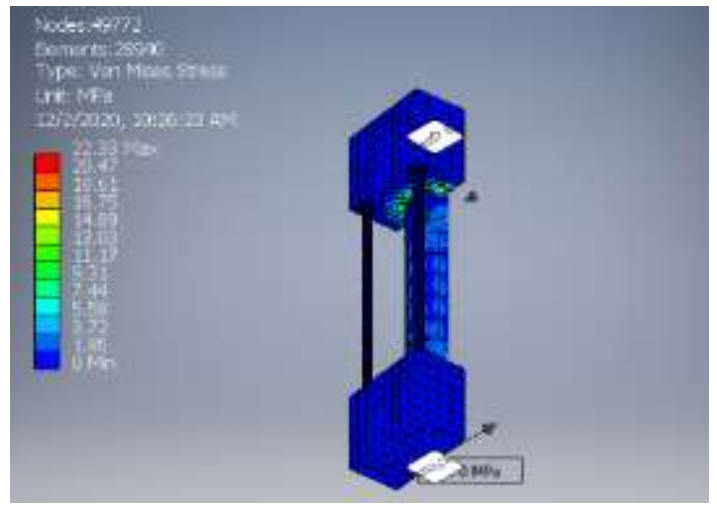

Gambar 8. Pengujian Stress

Dari simulasi pengujian menggunakan stress analysis inventor terlihat bahwa von mises stress untuk nilai maksimum 22.33 $\mathrm{MPa}$ dan nilai minimum sebesar $0 \mathrm{MPa}$. Dengan membandingkan hasil pengujian tekan ketebalan cylinder tube transparan, Gambar 6, maka cylinder tube transparan aman untuk dibuat. Bagian yang menunjukkan paling rawan pada tegangan yaitu bagian antara cylinder tube dengan tutup silinder atas dan bawah. Jika dilihat dari jenis beban yang paling berpotensi mengakibatkan kerusakan silinder yaitu pada tekanan yang dihasilkan.

Faktor keamanan juga diperhitungkan dimaksudkan agar seluruh komponen aman untuk digunakan. Pengujian safety factor dengan nilai maksimum sebesar 15 dan nilai minimum sebesar 7.62. Safety factor adalah batas kekuatan bahan menerima beban yang diberikan. Dapat dilihat pada Gambar 9 yang menunjukkan hasil analisis menampilkan distribusi faktor keamanan paling rendah bewarna merah sedangkan faktor keamanan paling tinggi bewarna biru. Untuk komponen yang mendapatkan beban berulang adalah 1-5 sedangkan komponen yang mendapatkan beban kejut 3-4. Hasil simulasi pengujian silinder menggunakan stress analysis inventor 2019 untuk safety factor di range minimal 7-8, maka dapat disimpulkan komponen silinder aman dengan tekanan 2.3 $\mathrm{MPa}$.

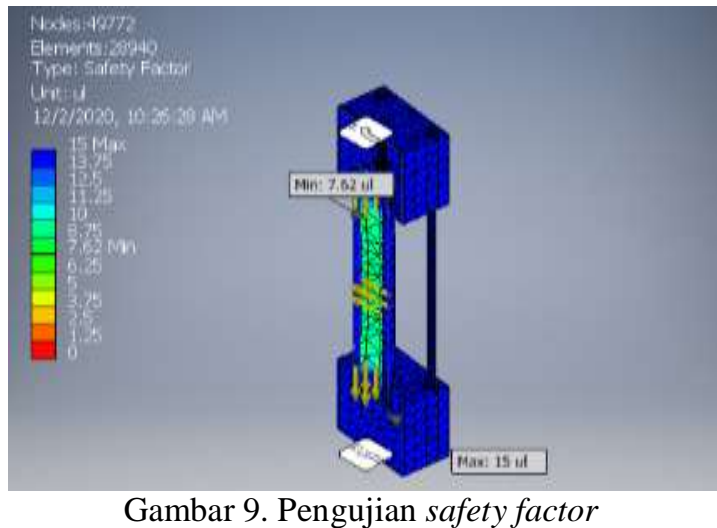

Ketika fluida dialirkan ke dalam silinder untuk mendorong piston dan piston rod, permukaan yang paling besar menerima tekanan dalam permukaan silinder. Oleh karena itu perlu dilihat seberapa besar peregangan yang terjadi akibat tekanan tersebut. Dalam simulasi ini nilai displacement menunjukkan besar peregangan yang terjadi, Gambar 10.

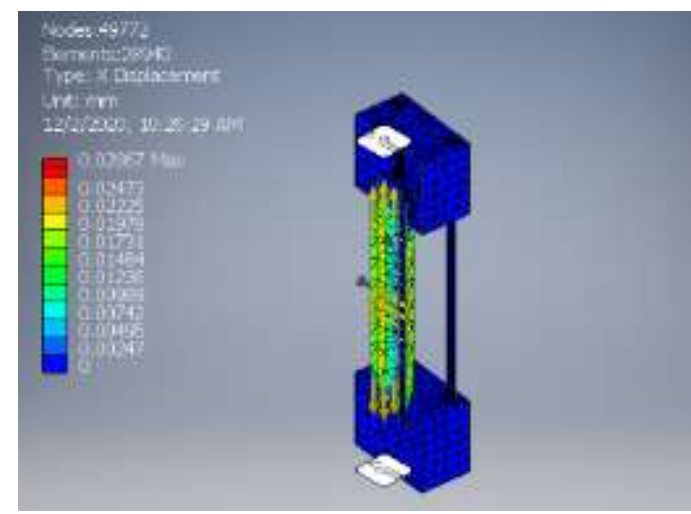

Gambar 10. Pengujian displacement silinder

Nilai maksimum dan minimum displacement adalah $0.02867 \mathrm{~mm}$ dan $0 \mathrm{~mm}$. Dari hasil displacement yang diperoleh masih dalam range aman tampak pada warna hijau dengan besaran nilai sekitar 0.0989 sampai dengan $0.01731 \mathrm{~mm}$.

Dari ketiga hasil pengujian cylinder tube von mises stress, displacement dan safety factor dengan menggunakan software Autodesk Inventor 2019 dapat disimpulkan silinder yang akan dibuat masih dalam kondisi aman dan dapat dilanjutkan pada proses pembuatan. Cylinder tube transparan dapat dilihat pada Gambar 11. 


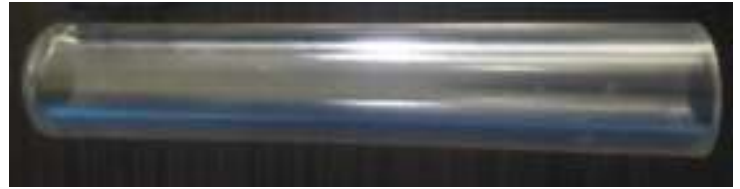

Gambar 11. Cylinder tube transparan

Pembuatan cylinder tube transparan dimulai dengan menghitung volume dari cylinder tube, kemudian menyiapkan cetakan cylinder tube, membuat campuran antara resin dan katalis sesuai dengan perbandingan dalam membuat sampel akrilik.

Setelah resin dan katalis tercampur sempurna, campuran tersebut dituang ke dalam cetakan cylinder tube. Waktu yang dibutuhkan untuk proses pengeringan adalah 24 jam.

Setelah seluruh komponen double acting cylinder transparan lengkap, tahapan berikutnya melakukan perakitan dan melakukan finishing dari hasil perakitan. Komponen-komponen double acting cylinder terdiri dari: tabung silinder transparan, tutup silinder (atas dan bawah), piston dan piston rod, seal hidrolik nipple in dan nipple out serta baut pengunci silinder. Berikut hasil prototipe double acting cylinder transparan, seperti pada Gambar 12.

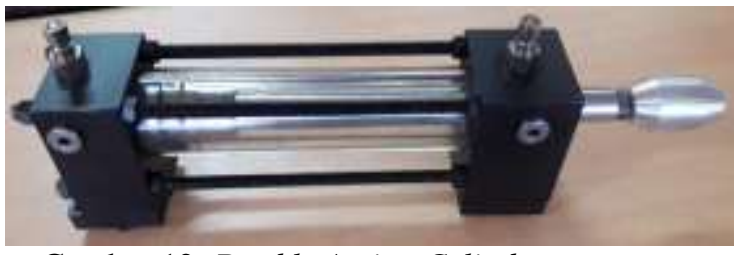

Gambar 12. Double Acting Cylinder transparan

Tahapan akhir dari penelitian ini adalah uji coba double acting cylinder transparan di Hydraulic Trainer dan menggunakan rangkaian elektrohidrolik. Uji coba yang dilakukan menggunakan hydraulic trainer Chung Pa. Rangkaian sistem hidrolik yang digunakan adalah rangkaian dasar elektrohidrolik katup kontrol arah 4/3 dua solenoid dan rangkaian dasar elektrohidrolik katup kontrol arah 4/2 dua solenoid serta menggunakan double acting cylinder transparan. Rangkaian dasar elektrohidrolik tersebut dapat dilihat pada gambar 12 dan Gambar 13.
Proses uji coba diawali dengan mempersiapkan komponen sistem hidrolik yang ada pada gambar rangkaian dasar. Langkah berikutnya adalah merangkai sistem hidrolik dan dilanjutkan dengan merangkai elektrohidrolik. Pada rangkaian elektrohidrolik peralatan yang digunakan adalah oil pump circuit breaker, power suplay, switch modul, dan relay modul.

Pada katup kontrol arah 4/3 dan 4/2 memiliki kode $\mathrm{P}, \mathrm{A}, \mathrm{B}$ dan $\mathrm{T}$. Kode $\mathrm{P}$ adalah saluran fluida yang berasal dari sumber pembangkit tekanan, kode A adalah saluran keluar fluida ke actuator hidrolik (double acting cylinder transparan), kode B adalah saluran keluar dari actuator hidrolik (double acting cylinder transparan) dan kode $\mathrm{T}$ adalah saluran untuk masuknya oli ke dalam tangki atau reservoir.

Setelah keseluruhan komponen terpasang, langkah berikutnya adalah mengatur tekanan dari sumber pembangkit tekanan sesuai dengan tekanan yang direncanakan yaitu 23 bar.

Pengoperasian sistem hidrolik dimulai dengan menekan tombol hijau 1, gerakan yang terjadi pada double acting cylinder transparan adalah gerak maju piston dan piston rod bila dinotasikan adalah gerak fluida dari saluran $\mathrm{P}$ menuju saluran A. Sedangkan bila tombol hijau 2 ditekan maka fluida akan bergerak dari saluran P menuju saluran B yang menyebabkan piston dan piston rod kembali ke posisi semula (mundur).

Pada saat fluida masuk ke saluran $\mathrm{P}$ menuju saluran A terlihat dengan jelas fluida mendorong piston dan piston rod, begitu juga bila fluida masuk ke saluran $\mathrm{P}$ menuju ke saluran B.

Proses pergerakan inilah yang menjadi acuan bahwa cylinder tube single acting cylinder dan double acting cylinder menghasilkan gerak lurus atau linier. 


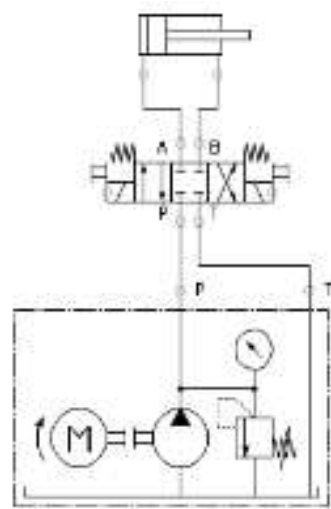

Gambar 13. Rangkaian katup kontrol arah 4/3

Untuk tata letak rangkaian katup kontrol 4/3 di hydraulic trainer, seperti pada Gambar 13.

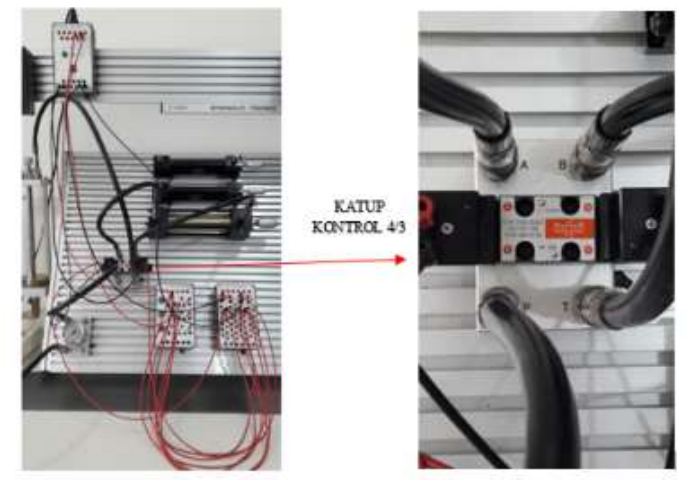

Gambar 14. Uji coba katup kontrol arah 4/3

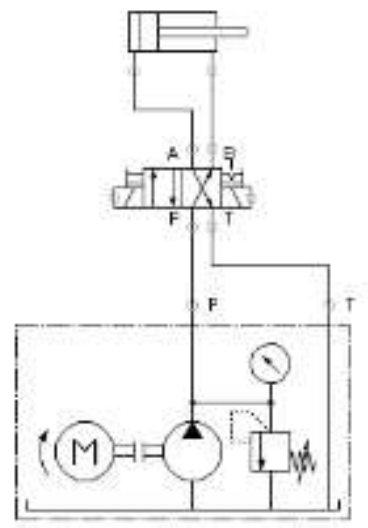

Gambar 15. Rangkaian katup kontrol arah 4/2

Untuk tata letak rangkaian katup kontrol 4/3 di hydraulic trainer, seperti pada gambar 15 .

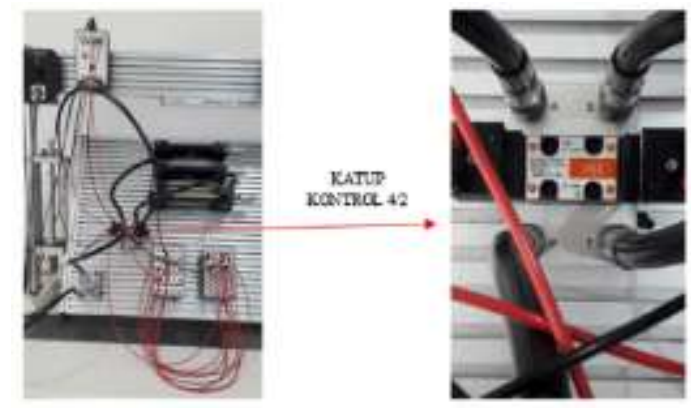

Gambar 16. Uji coba katup kontrol arah 4/2

Dari uji coba kedua rangkaian katup control tersebut tersebut, double acting cylinder transparan berfungsi dengan baik. Pada saat sistem hidrolik dioperasikan dapat terlihat, fluida (oli) yang masuk kedalam cylinder tube dapat menggerakan piston dan piston rod untuk melakukan pergerakan, baik pergerakan maju dan pergerakan mundur.

Selain itu juga terlihat seal hidrolik yang terpasang pada piston dapat membatasi antar ruang di dalam cylinder tube. Dalam pergerakannya terlihat seal hidrolik berfungsi dengan baik. Agar seal hidrolik tetap berfungsi, maka tekanan yang masuk ke dalam cylinder tube harus sesuai dengan tekanan yang direncanakan.

\section{Kesimpulan}

Setelah melakukan keseluruhan tahapan metode rancang bangun double acting cylinder transparan dilakukan dapat disimpulkan bahwa double acting cylinder transparan dapat digunakan dan berfungsi dengan baik. Double acting cylinder transparan dapat diaplikasikan pada rangkaian dasar elektrohidrolik katup kontrol arah 4/2 dan rangkaian dasar elektrohidrolik katup kontrol arah 4/3.

Saat rangkaian sistem hidrolik dioperasikan, fluida masuk ke dalam cylinder tube transparan dan mendorong piston rod sehingga gerakan linier double acting cylinder baik gerakan maju dan gerakan mundur dapat terlihat dengan jelas.

\section{Ucapan terimakasih}

Ucapan terima kasih disampaikan kepada lembaga dalam hal ini Politeknik Negeri Pontianak, khususnya Jurusan 
Teknik Mesin dan Pengelola Laboratorium Pneumatik dan Hidrolik yang telah memfasilitasi penelitian ini baik berupa dukungan moril dan finansial. Terima kasih juga kepada tim peneliti yang telah memberikan dukungan dan kontribusi sehingga penelitian ini dapat dipublikasikan di Jurnal Turbo.

\section{Referensi}

[1] Q.S. Khan, Design and Manufacturing Hydraulic Cylinder, Tanveer Publication, India

[2] Akash Khamkar, et al., 2019, Design Manufacturing and Testing of Transparent Acrylic Prototype of Hydraulic Brake Master Cylinder, International Research Journal of Engineering and Technology (IRJET), Volume 6.

[3] Stryczek J, et al., 2017, The Fluid Power Elemens and System Made of Plastics, Procedia Engineering Elsevier 176 (600-609)

[4] Festo Didactic, Hydraulic Training Unit TP501, Manual Book, Germany

[5] Chung $\mathrm{Fa}$, Hydraulic Control Technology CPE-Hy8000, Manual Book, Chungpa EMT Co. LTD, Korea Selatan

[6] ThankGod E., et al., 2017, Design and Finite Element Analysis of Double Acting, Double Ends Hydraulic Cylinder for Industrial Automation Application, American Journal of Engineering Research (AJER), Volume-6, Issue-3, pp-131- 138

[7] R. S. Khurmi and J. K. Gupta, 2005, Machine Design, 14 th revised edition, Eurasia Publishing House (PVT) LTD, Ram Nagar, New Dehli,

[8] George E Totten, Victor J De Negri, 2012, Handook of Hydraulic Fluid Technology Second Edition, CRC Press, Taylor and Francis Group, Boca Raton

[9] Peter Chapple, 2015, Principles of Hydaulics System Design Second Edition, Momentum Press, New York
[10] K.L. Narayana, et al., 2006, Machine Drawing Third Edition, New Age International (P) Limited Publisher, New Delhi 